\title{
Desktop photos
}

$\mathrm{T}$ he small photograph that sits alone on the office desk of a surgical colleague tells a life-saving story. Indicative of its importance to him, the photo has rested on his desk since the day he first occupied the office nearly a decade ago. Like the other artifacts he has placed around the room, though, each chosen for its meaning or its beauty, over time the photo has assumed a background role. He hardly notices the objects as he does his work there. Attention is directed instead toward papers that cross his desk, images that come and go on his computer screen, work on the phone, staff and colleagues entering and leaving, and ever-present thoughts in between about clinical or administrative issues. But the manner in which he attends to these tasks, the way he treats his patients, even how he performs their operations, has much to do with the stories the artifacts tell. They are reflective of the formative and sustaining things he has experienced that make him the doctor and person he is. On a recent occasion he did take the picture off his desk to look at it, and what it conjured up brought him to tears. For the life saved in the story the picture tells is not the life of a patient, but of his own family.

The picture shows two little girls in their pajamas sitting on a bed holding a telephone. They are saying good night to him, their father, still at work. This they commonly did since he was a member of a group that scheduled operations well into the evening. Present in the scene, though not in the picture, is the girls' mother, who took the photo for reasons and feelings of her own. The scene speaks of innocence, separation, unfortunate and recurring compromise - and hints at possible regrettable future realities.
Inscribed on the picture are the words "Thank You Daddy" — an obscure inclusion, until he explains "Thank You Daddy" was written by the girls later, the picture then framed and presented to their father in thanks for his leaving that practice for one that allowed him to be home most evenings. The completed scene speaks of caring, responsiveness, op- timism and wholeness. The photo serves as an emotive reminder for him of what was and might have been and of what is, the family together and well, and he perhaps the most thankful of all for having made the decision he did.

\section{Lawrence J. Hergott} Denver, Colo.

\section{Poem}

\section{Rosie's dementia}

\author{
Damn you! \\ Bring me some water. \\ Leave me alone. \\ I don't want you here. \\ Heyyy - come here! \\ Are you Sally? \\ Where am 1? \\ Get out of here!
}

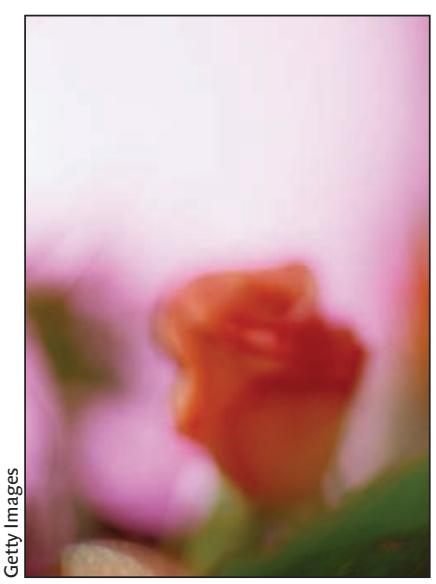

Bring me some food.

Who are you?

Do you like my red dress?

Where am I?

Cold, lost stares, a tragedy of solitary fragments of tangled memory.

She, in her vermilion gown, unsure of everywhere, unsure of everyone.

Nightfall, head cocked downward, neck bent in a bizarre contortion. Sleep dawning, her muted memory now resting.

Paul Rousseau Phoenix, Ariz. 